\title{
Informed Consent Document (ICD) as Educational Tool for Medical School
}

\author{
Prithpal S. Matreja ${ }^{* 1}$, Amandeep Singh ${ }^{1}$, Ashwani K Gupta ${ }^{1}$ Jaspreet Kaur $^{2}$
}

Department of Pharmacology, Gian Sagar Medical College and Hospital, Ram Nagar, District Patiala 140601 India ${ }^{1}$.

\section{ARTICLE INFO}

Received

$: 11 / 05 / 2012$

Accepted

: 09/10/2012

Published

: $01 / 06 / 2013$

\section{KEYWORD}

Medical Education,

Informed Consent Document,

Clinical Research,

Assessment,

Educational Tool

\section{ABSTRACT}

Introduction: India is fast becoming a hub for clinical research. A lot of clinical research is being done at all levels of the health care system and Physician assumes a central role in it. There is even shift of focus about imparting clinical research training to medical students, as at some stage of their practice they will be involved in clinical research. Informed Consent Document forms a central basis of ethical clinical research and is considered a priority as per Schedule Y, ICH-GCP guidelines and Declaration of Helsinki. Objective: To assess the knowledge, understanding and attitude of medical students about Informed Consent Document before and after imparting training to the medical students Method: This prospective study was conducted in the Department of Pharmacology, Gian Sagar Medical College, Patiala. Ninety five medical students in the final year of their MBBS course were enrolled in the study and were given a questionnaire before and after imparting training about informed consent document as per Schedule Y, ICH-GCP guidelines and Declaration of Helsinki. Result: The students were assessed on their knowledge and attitude about informed consent document. After the training, the students were significantly ( $\mathrm{p}<$ 0.05) more aware about the role of the Informed consent document as per guidelines. Also, there was a significant difference $(\mathrm{p}<0.05)$ in the pattern, behaviour and outlook of students after training was imparted to them. Conclusion: Training medical students about informed consent document significantly increased their knowledge, understanding and attitude.

(c) Medical Education Department, School of Medical Sciences, Universiti Sains Malaysia. All rights reserved.

CORRESPONDING AUTHOR: Dr Prithpal S Matreja Department of Pharmacology, Gian Sagar Medical College and Hospital, Village Ram Nagar, Tehsil Rajpura, District Patiala, Punjab 140601 India $^{2}$

Email: drpsmatreja@yahoo.co.in 


\section{Introduction}

Informed consent is the right of every volunteer or patient who is participating in a clinical research, contributing to the good of mankind. It implies trust of the participant on the researcher. In all trials or medical research's, a freely given, informed written consent is required to be obtained from each study subject or the subject's legally acceptable representative. The investigator / physician must provide information about the study verbally as well as using a patient information sheet, in a language that is non-technical and understandable by the study subject or subject's legally acceptable representative and the impartial witness. The participants or their legally acceptable representative should be given ample time and opportunity to inquire, deciding whether or not to participate and all questions should be answered to satisfaction. The Subject's written consent must be then obtained using an 'Informed Consent Form'. Privacy and confidentiality are other important rights of volunteer or patient that should be taken care of $[1,2,3]$.

This paper deals with the informed consent related to participation in clinical research, and should not be confused with consent to treatment. As explained in the Declaration of Helsinki, research participants must receive adequate information pertaining to the project's aims, methods, expected benefits, and potential hazards and discomforts. It is the ethical and legal responsibility of the physician in medical research to protect the life, health, privacy, and dignity of the participant. Researcher should thus be aware of the ethical, legal and regulatory requirements for research on human subjects in their own countries as well as applicable international requirements [4]. The Good Medical Practice guidelines by General Medical Council of United Kingdom states that the volunteers or patients must give informed consent to any activity, including participating in teaching or research, as well as in any activity undertaken by a medical student. The students should be aware of ethical issues in their professional behaviour with patients and make sure that patients have consented and follow guidance on confidentiality [5].

A study comparing the awareness of doctors in Malaysia and Kashmir, India about informed consent showed that most $60 \%$ of the doctors were neither aware of the existence of ethics committee nor the pattern of consent. The results of the study emphasized the need for doctors to change their attitude and acknowledge the patient's autonomy [6].

To the best of our knowledge, training about informed consent document (ICD) in undergraduate medical education is lacking and since they would be tomorrow's doctors, they should be aware of the process of ICD. Hence, it was considered worthwhile to assess the awareness of students and to impart training on ICD as an educational tool.

Objectives: To assess the knowledge, understanding and attitude of medical students about Informed Consent Document before and after imparting training to the medical students.

\section{Method}

This prospective study was conducted in Department of Pharmacology, Gian Sagar Medical College and Hospital, Patiala. Hundred students in the Final year of MBBS were selected to participate in the study. The Final year MBBS students were chosen as they were completing their undergraduate medical education in less than a year and they would start their internship. These students were provided with a self administered questionnaire (SAQ) (Appendix 1); prior to their training on ICD. The questionnaire was provided in a sealed envelope and opened simultaneously to avoid any bias. Students also had to make sample research projects with ICD which was assessed by faculty trained in ICH-GCP guidelines and not by any of the study members. The questionnaire consisted of 20 questions and answer to each question was supposed to be yes / no / not sure. This would enable us to assess their basic knowledge and belief about ICD. This study was approved by the Institutional Ethics Committee (IEC) of Gian Sagar Medical College and Hospital, Patiala, 
India. Those students who gave a written informed consent were enrolled in the study.

Six hour training spread over one week was then imparted to these medical students. There was a series of presentation in the form of a power point presentation, describing about the history, procedure, method, content of ICD, some common mistakes done during procedure of ICD, and various components of ICD by the study team.

This training was then followed by the assessment of the students. This assessment was done using the same questionnaire given before the training. The assessment looked into the knowledge, attitude and understanding of the student.

\section{Result}

A total of 100 students of final year MBBS took part in the study, 5 students did not come for the training part, hence were excluded from the statistical data analysis. Of the 95 students 55 were girls and 40 were boys.

All the 95 students completed the questionnaire before and after imparting the training on Informed consent document. The pattern in which the questionnaire was attempted showed that most of the students were aware about some basic components of the informed consent document.
The students had basic knowledge about consent form like the language of consent form, all details of the study/trails should be given to the patient, the physician should also date and sign the consent form, the doctor cannot sign on behalf of patient, there should be no influence on patient to sign the consent form, therapy should be initiated only after consent, a witness is required who should not be under any influence (Table 1 and Figure 1).

The students were not aware of the difference in the consent which is signed by the patient for routine therapy as compared to the consent for a particular research/trial. The questions which were routinely followed to obtain consent, the students attempted them with ease. However, there was a significant difference in their knowledge regarding the ICD which is followed for a research protocol/study. More than $80 \%$ of students were aware after training that ICD is taken to safeguard the patients, patient can withdraw from the study any time even after giving informed consent, the physician should treat the patient even if he withdraws from study, ICD should be taken before enrolling the patient, the patient can taken any number of days to sign ICD, a copy of ICD should be given to the patient, the ICD should have minimum number of scientific terms, there should be contact details of physician and his team in ICD and confidentiality of patients should be maintained. 
Table 1: Response of students before and after training about ICD

\begin{tabular}{|c|c|c|c|c|c|}
\hline \multirow{2}{*}{ Questions } & \multicolumn{2}{|c|}{$\begin{array}{c}\text { Before } \\
\text { Training }\end{array}$} & \multicolumn{2}{|c|}{$\begin{array}{c}\text { After } \\
\text { Training }\end{array}$} & \multirow{2}{*}{ p value } \\
\hline & $\begin{array}{l}\text { Yes } \\
(\mathbf{n})\end{array}$ & $\begin{array}{l}\text { No } \\
(\mathbf{n})\end{array}$ & $\begin{array}{l}\text { Yes } \\
(\mathbf{n})\end{array}$ & $\begin{array}{l}\text { No } \\
(\mathbf{n})\end{array}$ & \\
\hline $\begin{array}{l}\text { 1. Informed consent document is to safeguard the treating physician. } \\
\text { (A) }\end{array}$ & 23 & 72 & $5^{*}$ & 90 & $<0.05$ \\
\hline 2. Informed Consent document can be in any language. (U) & 71 & 24 & $75^{*}$ & 20 & $<0.05$ \\
\hline $\begin{array}{l}\text { 3. Once patient signs the Informed consent Document he will have to } \\
\text { continue in the study/ trial. }(\mathrm{K})\end{array}$ & 70 & 25 & 15 & 80 & 0.15 \\
\hline 4. Only the patient should sign and date a written ICD. (A) & 18 & 77 & $13 *$ & 82 & $<0.05$ \\
\hline $\begin{array}{l}\text { 5. There is no need to give the details of study/ trial to the patient } \\
\text { except for the adverse drug reactions. (U) }\end{array}$ & 13 & 82 & $7 *$ & 88 & $<0.05$ \\
\hline $\begin{array}{l}\text { 6. If patient does not sign the ICD the Physician should not treat him. } \\
\text { (A) }\end{array}$ & 71 & 24 & $10 *$ & 85 & $<0.05$ \\
\hline $\begin{array}{l}\text { 7. ICD should be taken after enrolling the patient to the study/trial. } \\
\text { (U) }\end{array}$ & 64 & 31 & $8 *$ & 87 & $<0.05$ \\
\hline $\begin{array}{l}\text { 8. If the patient is illiterate the doctor/ medical staff can sign on } \\
\text { behalf of patient after explaining him about the study. }(\mathrm{K})\end{array}$ & 10 & 85 & $8 *$ & 87 & $<0.05$ \\
\hline $\begin{array}{l}\text { 9. ICD can be taken from a patient by providing him with some gains } \\
\text { in term of economical or medical gains. (A) }\end{array}$ & 11 & 84 & $6 *$ & 89 & $<0.05$ \\
\hline $\begin{array}{l}\text { 10. Therapy can be started in patient prior to taking ICD and it can be } \\
\text { taken at later stage after the patient has orally accepted to participate. } \\
\text { (K) }\end{array}$ & 10 & 85 & $4 *$ & 91 & $<0.05$ \\
\hline $\begin{array}{l}\text { 11. The patient should sign the ICD on the day in which he is } \\
\text { explained about the study. (U) }\end{array}$ & 69 & 26 & $6^{*}$ & 89 & $<0.05$ \\
\hline 12. There is no need to give a copy of ICD to the patient. $(\mathrm{K})$ & 65 & 30 & $12 *$ & 83 & $<0.05$ \\
\hline 13. There is no need for witness to sign the ICD. (U) & 15 & 80 & $11 *$ & 84 & $<0.05$ \\
\hline 14. A witness can be a paramedical staff. $(\mathrm{K})$ & 12 & 83 & $10 *$ & 85 & $<0.05$ \\
\hline $\begin{array}{l}\text { 15. If the patients withdraw after signing the ICD the doctor should } \\
\text { not treat him. (A) }\end{array}$ & 65 & 30 & $9 *$ & 86 & $<0.05$ \\
\hline 16. The ICD should contain scientific terms. $(\mathrm{K})$ & 25 & 70 & $10 *$ & 85 & $<0.05$ \\
\hline 17. The ICD can be signed by any one in emergency. (U) & 15 & 80 & $11 *$ & 84 & $<0.05$ \\
\hline 18. The ICD is not required in case of emergency. $(\mathrm{K})$ & 14 & 81 & $9 *$ & 86 & $<0.05$ \\
\hline 19. The ICD should contain the contacts of treating Physician. (U) & 13 & 82 & 68 & 27 & 0.28 \\
\hline $\begin{array}{l}\text { 20. If the patient signs the ICD his particulars can be disclosed to all } \\
\text { the physician. (A) }\end{array}$ & 51 & 44 & $16^{*}$ & 79 & $<0.05$ \\
\hline \multicolumn{6}{|l|}{${ }^{*} \mathrm{p}<0.05$ as compared to before training using McNemar's Test } \\
\hline Measured outcomes: knowledge (K), understanding (U) and attitude & & & & & \\
\hline
\end{tabular}




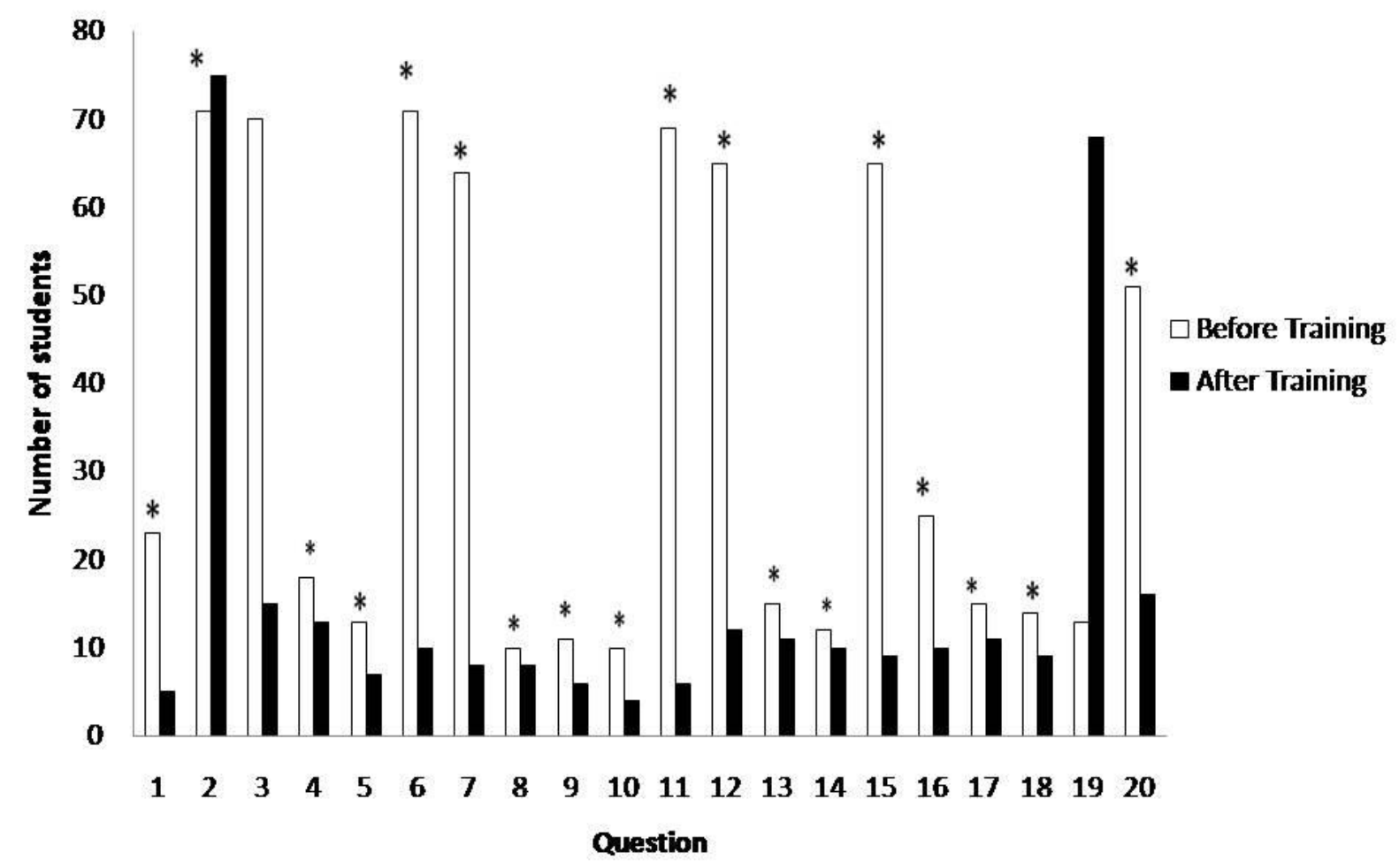

Figure 1: Comparison of response of students before and after training

\section{Discussion}

The purpose of this study was to determine the effect of formal training on informed consent process for conducting clinical trials on the medical student's knowledge, attitudes and understanding about informed consent. Our study demonstrated that statistically significant differences are produced in the knowledge, understanding and attitude of students on ICD after week-long training of medical students. Informed consent document (ICD) is defined as "A process by which a subject voluntarily confirms his or her willingness to participate in a particular trial / medical research, after having been informed of all aspects of the trial that are relevant to the subject's decision to participate. Informed consent is documented by means of a written, signed and dated informed consent form." [1]

To assess the knowledge of medical students on Informed Consent, we created a questionnaire as per the components of Declaration of Helsinki, Schedule Y of the Drugs and Cosmetics Act of India, and ICH-GCP $[1,2,4]$. At the beginning of the study, this questionnaire was administered to students without any formal training about the informed consent process. To assess the effect of training of informed consent process on medical students, we carried out 6-hour training for final year medical students extended over a period of one week. According to the finding at the end of the training, most of the students were found to have gained a good knowledge on the informed consent process - oral or written; the time of obtaining the consent during the study; the adequacy of the information regarding the research that needed to be given to the patient objectives and methodology of the research, risks and benefits involved, their safety, duration of study, freedom to choose to participate or not in the clinical study, physician contacts, confidentiality of the patient, other treatments or alternatives available, the right to withdraw from the study at any time without any risk with regard to the quality of the usual treatment; what to do if the patient is not capable of signing the consent; economical or medical gains; language of ICD required. 
The basic purpose of informed consent is that it is meant to guarantee the voluntary nature of participation in research. For this the research personnel must explain to the subjects in simple terms the experimental nature of the study, the implications of their participation in the trial and to give them the assurance that their rights, safety, and well-being are preserved and protected. They should ensure that the participant understands the importance of the information and thus make them fully capable of making an informed decision about whether or not to participate in the clinical trial [7, 8].

The formal training of informed consent process has not been debated to the extent it requires attention. No training regarding informed consent process is given during the course of undergraduate curriculum in India. Those who are trained, get their training when they conduct some trials from a person deputed by the sponsors, or they ask the person deputed by the sponsors to get the informed consent signed which may be biased and unethical. In a survey conducted by Association of Physicians of India, physicians were shown to have very less knowledge of the informed consent process [9]. Even if the physicians had some knowledge of the informed consent process, they did not stick to the ethical principles of the Informed consent process [6].

Thus, to increase the knowledge of doctors regarding informed consent (IC), the training of informed consent process and medical ethics should be included in the medical curriculum, especially in the $2^{\text {nd }}$ year, so as to inculcate the values of medical ethics in medical students before they encounter real-life patients and clinical research. This would also be a teaching ground for ethical examination and consent to treatment of patients. And it does not have to take much effort on the part of medical schools to improve the skill. The duration of training, its contents, and the teaching methodology of this educational tool have not yet been completely determined. However, to improve the doctor's skill on medical ethics and informed consent process two to three $1-1 \frac{1}{2}$ hour session in a single day or spread over few days is needed.
Emphasis should be given to ethics, understanding and communication skills imparting authoritative information and protecting the patient's right to choose [10]. Doyal et al published a document in 2001 that provides a detailed guide for clinical teachers to ensure proper medical student-patient interaction during training. As medical educators, it is our responsibility to adhere to ethical and legal guidelines when interacting with patients, this might act as a model for students and thus for future doctors $[11,12,13]$.

The doctor-patient relationship is predominantly governed by trust. With a lot of money being involved in conducting trials, and supported by overburdened health services, low literacy levels and poverty in India, the informed consent process may be biased and may act against the research participants [14, 15]. An important medico-legal concern is improper consent and withholding complete information from the patient. However in recent years, patients' increasing awareness of their rights has resulted in more formal complaints being filed. Every day, cases of negligence and malpractice are being brought to courts, and debated in the press regarding ethical issues of the medical practitioners all over the world. This has exerted pressure on the medical profession and government to ensure that unethical practices are challenged and prevented. So, protecting human subjects from unethical research has been a prominent issue in recent years. In India, the foundation stone of consumer courts was laid by the introduction of Consumer Protection Act (CPA) in 1986, and this was made firm by the landmark judgment of Supreme Court of India in November 1995 by including the healthcare professionals under the CPA [16, 17].

\section{Conclusion}

Formal education on informed consent to the medical community should be regarded as a method to improve health rather than as a method to avoid legal responsibility. Physicians who are short of the skills of appropriately informing patients and obtaining proper 
informed consent should be viewed as lacking essential medical skills necessary for practice.

Following the training, the medical students gained knowledge and awareness of ethical issues as well as developed favourable attitudes and skills of obtaining informed consent. It helped them to differentiate the informed consent used for clinical trial from the consent used for routine therapy. This was supported by the feedback from the students and that they gained the confidence to approach the research participants for informed consent process. This study was conducted among students of final year MBBS, in a single academic medical college and hospital. Additional research about informed consent from the physician point of view should be undertaken.

\section{Reference}

1. ICH Harmonised Tripartite Guideline [Internet]. Guideline for Good Clinical Practice E6 (R1). 1996 [cited 2011 Jan 8] Available from: http://www.ich.org/fileadmin/Public_Web_S ite/ICH_Products/Guidelines/Efficacy/E6_R 1/Step4/E6_R1_Guideline.pdf

2. Schedule Y [Internet]. Requirements and Guidelines for permission to import and / or manufacture of new drugs for sale or to undertake clinical trials. 2000 - [cited 2011 Jan 8]. Available from: http://cdsco.nic.in/html/scheduley\%20\%28amended\%20version2005\% 29\%20original.htm

3. Badzek L, Gross L. Confidentiality and privacy: at the forefront for nurses. Am J Nurs 1999; 99:52-4.

4. World Medical Association Declaration of Helsinki [Internet]. Ethical Principles for Medical Research Involving Human Subjects. c1964-2008. [cited 2011 Jan 8]. Available from: http://www.wma.net/en/30publications/10po licies/b3/index.html

5. General Medical Council [Internet]. Medical Students: professional behaviour and fitness to practise. 2007 [cited 2011 Jan 09]. Available from: http://www.gmcuk.org/guidance/good_medical_practice.asp

6. Yousuf R M, Fauzi A R M, How S H, Rasool A G, Rehana K. Awareness, knowledge and attitude towards informed consent among doctors in two different cultures in Asia: a cross-sectional comparative study in Malaysia and Kashmir, India. Singapore Med J 2007; 48(6):559-65.

7 Faden RR, Beauchamp TL. A history and theory of informed consent. New York: Oxford University Press, 1986.

8 Appelbaum PS, Roth LH. Competency to consent to research. Arch Gen Psychiatry 1982; 39: 951-8.

9 Sriram TG, Chatterjee S, Jain $\mathrm{S}$, et al. Opinion survey of physicians on ethical issues in medical research. J Indian Med Assoc 1991; 89: 187-90.

10 Arda B, Oğuz N Y, Şahinoğlu S. Informed Consent in Medical Education: The Experience of the Medical Ethics Department of Ankara University Medical School. Journal of Ankara University Faculty of Medicine 2009; 62(4):143-7.

11 Doyal L: Closing the gap between professional teaching and practice. BMJ 2001; 322(7288):685-6.

12 Hicks LK, Lin Y, Robertson DW, Robinson DL, Woodrow SI: Understanding the clinical dilemmas that shape medical students' ethical development: questionnaire survey and focus group study. BMJ 2001; 322: 70910.

13 Barnett AT, Cawich SO, Crandon IW, Lindo JF, Strachan GG, Robinson D, et al. Informed consent from patients participating in medical education: a survey from a university hospital in Jamaica. BMC Research Notes. 2009 Dec [cited 2011 Jan 9]; 2: 252 [about 5 p.]. Available from: http://www.biomedcentral.com/17560500/2/252

14. Bansal Y S, Singh D. Medico-legal aspects of informed consent. Ind $\mathrm{J}$ Forensic Med Toxicology 2007; 1: 19-23.

15. Bal A. Informed consent - legal and ethical aspects. Issues Med Ethics 1999; 7(2): 56-7.

16. Supreme Court of India. Judgments, the judgment information system of India. Civil appeal no: 688 of 1993. Supreme Court of India [Internet]. 1995 Nov 13 [cited 2011 Jan 9]. Available from: http://judis.nic.in/supremecourt/imgs.aspx

17. Supreme Court of India. Judgments, the judgment information system of India. Civil appeal no: 1949 of 2004. Supreme Court of India [Internet]. 2008 Jan 16 [cited 2011 Jan 9]. Available from: http://judis.nic.in/supremecourt/imgs.aspx 